\title{
GOVERNANÇA DE TECNOLOGIA DA INFORMAÇÁO COMO FERRAMENTA DE OBTENÇÃO DE VANTAGEM COMPETITIVA NAS ORGA̧NIZAÇÓES
}

\author{
Information Technology Governance as a tool for achieving aompetitive \\ advantage in organizations
}

Gobernanza de Tecnología de la Información como herramienta de obtención de ventajas competitivas en las organizaciones

Marcelo Nassif de Magalhães ${ }^{1}$

\section{RESUMO}

Esta pesquisa tem o caráter exploratório e bibliográfico em formato de ensaio e busca estudar como a governança de Tecnologia da Informação pode auxiliar as organizaçôes na obtenção de vantagem competitiva. Para isto, foram estudados diversos artigos publicados sobre o assunto. Conclui-se que, se adotados os critérios de governança de TI para a obtenção de vantagem competitiva na organizaçáo, a possibilidade de sucesso é grande, desde que os gestores realizem uma boa gestão financeira, empregando adequadamente os critérios de governança de TI e sigam o modelo de Chi e Sun (2015). Para que a governança de TI atenda aos preceitos da obtençáo de vantagem competitiva, deve-se: a) Agregar valor; b) Ajudar a empresa na proteção de integridade de um produto raro, que ela venha a elaborar, lançar e comercializar; c) Auxiliar a empresa na proteção da integridade das informaçóes necessárias para a elaboração, criação e comercialização de um produto difícil de ser imitado; e d) Auxiliar a empresa na proteção da integridade das informações necessárias para elaborar, lançar e comercializar um produto insubstituível.

PALAVRAS-CHAVE: Gestão. Governança Corporativa. Governança de TI. Vantagem Competitiva.

\section{ABSTRACT}

The kind of this research is exploratory and bibliographic. This is an essay and seeks to study how Information Technology Governance can assist organizations in obtaining Competitive Advantage. For this, several articles published on the subject have been studied. It is concluded that if IT Governance

1 Mestre em Administração pela UNIGRANRIO, Contador registrado junto ao Conselho Regional de Contabilidade do Estado do Rio de Janeiro e Gerente de Projetos; Professor, Membro do Núcleo Docente Estruturante (NDE) e atual Coordenador Acadêmico da Área de Ciências Contábeis da Faculdade Cenecista de Rio das Ostras - CNEC.marcelo_nassif@oi.com.br. 
criteria are adopted to obtain a competitive advantage in the organization, the possibility of success is great, as long as the managers perform a good financial management, properly using the IT Governance criteria and follow the model of Chi and Sun (2015). In order for IT Governance to comply with the precepts of obtaining competitive advantage, it must: a) Added value; b) To help the company in the protection of the integrity of a rare product, that it will elaborate, to launch and to commercialize; (c) to assist the undertaking in protecting the integrity of the information necessary for the preparation, creation and marketing of a product which is difficult to imitate; and d) Assist the company in protecting the integrity of the information necessary to design and launch and market an irreplaceable product.

KEYWORDS: Competitive advantage. Corporate governance. IT governance. Management.

\section{RESUMEN}

Esta investigación tiene el carácter exploratorio y bibliográfico en formato de ensayo y busca estudiar cómo la gobernanza de Tecnología de la Información puede auxiliar a las organizaciones en la obtención de ventaja competitiva. Para ello, se estudiaron diversos artículos publicados sobre el tema. Se concluye que, si se adoptan los criterios de gobernanza de T.I. para obtener una ventaja competitiva en la organización, la posibilidad de éxito es grande, siempre que los gestores realicen una buena gestión financiera, empleando adecuadamente los criterios de gobernanza de T.I. y sigan el mismo modelo de Chi y Sun (2015). Para que la gobernanza de T.I. atienda a los preceptos de la obtención de ventaja competitiva, se debe: a) Agregar valor; b) Ayudar a la empresa en la protección de la integridad de un producto raro, que ella vaya a elaborar, lanzar y comercializar; c) Auxiliar a la empresa en la protección de la integridad de las informaciones necesarias para la elaboración, creación y comercialización de un producto difícil de imitar; y d) Auxiliar a la empresa en la protección de la integridad de las informaciones necesarias para elaborar y lanzar y comercializar un producto insustituible.

PALABRAS CLAVE: Gestión. Gobierno Corporativo. Gobernanza de T.I. Ventaja competitiva.

Data de submissão: 28/04/2017

Data de aceite: 05/04/2018 


\title{
1 INTRODUÇÁO
}

Segundo Melo (2008), a Tecnologia da Informação (TI) é vista como uma forte ferramenta para obtenção de competitividade entre as empresas. Para isto, ela precisa estar alinhada aos negócios da empresa, de modo que os objetivos estratégicos da organização sejam atingidos, atuando de maneira a eliminar barreiras que inibam ou interfiram nas suas operaçôes ou negócios.

\begin{abstract}
A TI vem impactando os negócios de uma maneira jamais vista e está cada vez mais no domínio do negócio. Assim, a TI está adquirindo uma função de agente de desenvolvimento e de definição de estratégias em diferentes níveis (corporativo, de negócio e até mesmo funcional). Para atender a essas necessidades, o modelo de sistemas de informação das organizaçôes contemporâneas deve ser o mais abrangente, flexível e completo possível (MELO, 2008, p. 5).
\end{abstract}

Porém, para Becker, Lunardi e Maçada (2012), muitas empresas que não tiveram os mecanismos de Governança Corporativa embutidos em seus processos internos ou tiveram uma estratégia deficiente vieram a falir ou a ter gastos desnecessários nos seus projetos malsucedidos ou de custos elevados, com vários replanejamentos.

Então, replicando os conceitos de Governança Corporativa na TI, em busca de melhores resultados, surge a Governança de TI, que possibilita extrair algumas vantagens, Weill e Ross (2004) fizeram uma pesquisa que atestaram que empresas de topo, que executam a governança de TI geram retorno sobre seus investimentos em até quarenta por cento sobre seus concorrentes.

Neste sentido, levanta-se a seguinte questão: como a governança de TI pode ajudar as organizaçóes na obtenção de vantagem competitiva?

Buscando responder a esse questionamento a partir das possibilidades apresentadas pela literatura, foi elaborada esta pesquisa, no formato de ensaio, apontando o que de mais recente, no contexto de governança de TI, pode esclarecer esta questão.

Como esta pesquisa segue o princípio de um ensaio, foram estudados artigos publicados a partir de 2003 até o ano de 2015, excetuando-se a base de conhecimento de Vantagem Competitiva ditada por Porter (1990) e Barney (1991), que são as referências até hoje utilizadas por pesquisadores.

O ensaio buscou apresentar respostas sobre como a governança de TI (GTI) pode auxiliar na obtençáo de vantagem competitiva, identificar as ferramentas tecnológicas de GTI disponíveis para a obtenção de vantagem competitiva, auxiliar o meio acadêmico, alunos e professores universitários, a conhecer um pouco mais desta ferramenta complementar à governança corporativa, além de auxiliar os gestores no posicionamento e no emprego adequado da GTI. 


\section{VANTAGEM COMPETITIVA}

Deve-se iniciar o estudo, questionando o que é vantagem competitiva? Segundo Brito e Brito (2012), a vantagem competitiva é considerada como a principal hipótese para explicar o desempenho superior das empresas e representa o objetivo fundamental da gestão estratégica, estando sujeita a diferentes interpretaçôes. Observa-se a dificuldade de uma organização conceituar Vantagem Competitiva (VC) a partir das informações que ela detém. Para tal explicação é necessário compreender o que é custo de oportunidade e disposição a pagar do cliente.

Para Brito e Brito (2012, p. 365), "custo de oportunidade é o valor mínimo que o fornecedor está disposto a vender seus serviços e/ou produtos”. Portanto, o custo de oportunidade é indeterminável de forma absoluta e o seu valor é o resultado do processo de barganha sobre o valor já criado ou sobre a expectativa de valor no futuro. Pode-se dizer que o custo de oportunidade é o custo operacional mais uma pequena margem de lucro que a empresa está disposta a receber pela venda de seu produto ou serviço, sem que haja perdas para a organização (LIPPMAN e RUMELT, 2003).

Na literatura de marketing, o conceito de disposição a pagar representa o valor monetário que inclui todo o benefício que o cliente aufere no uso do consumo do produto. Logo, para Brito e Brito (2012), "VC é o escopo entre a disposição de pagar e o Custo de Oportunidade da empresa".

Mas, como iniciaram os estudos sobre vantagem competitiva? Analisando a dinâmica do mercado, Porter (1990) identificou cinco forças competitivas que, em conjunto, auxiliam a organização a se posicionar melhor perante o mercado. São elas: ameaça de novos entrantes, intensa rivalidade entre os concorrentes, pressão por produtos substitutos, poder de negociação tanto dos compradores, como dos fornecedores.

De imediato, pode ser observado que o poder de negociação de compradores, a intensa rivalidade da concorrência e a pressão por produtos substitutos estâo diretamente relacionados à disposição a pagar. Isto porque, segundo Porter (1990), se o produto ou serviço for muito comum, cada empresa lançará o seu preço muito próximo um do outro. Assim, os compradores terão um leque maior de opçôes, até porque o produto em questão não é difícil de encontrar.

Ainda seguindo a linha raciocínio de Porter (1990), o poder de negociação dos fornecedores e a ameaça de novos entrantes estão diretamente relacionados ao custo de oportunidade. Isto porque se o fornecedor tiver um elo de dependência muito forte com a empresa, irá ceder nos seus preços, aumentando a possibilidade de redução de custo de oportunidade. Situação semelhante ocorrerá com a questão de novos entrantes: Se entrar alguma 
empresa que forneça o mesmo produto ou serviço, no mesmo nicho de negócio, com um preço mais acessível, ou melhor, o custo de oportunidade tende a cair.

Porter (1990) informa que, para se sustentar uma VC, ela deve render um desempenho superior em longo prazo. Em seguida, Barney (1991) defende que, essa sustentabilidade a que se refere o termo não diz respeito aos efeitos da vantagem competitiva sobre o desempenho, mas à capacidade de manutenção da estratégia de criação de valor pela empresa.

Baseado nos conceitos de valor agregado, raridade, dificuldade de imitar e ser insubstituível, Barney (1991), afirma que se a organização formular estratégias frágeis, passíveis de imitação e superação pelos competidores, estas estratégias renderão apenas uma vantagem temporária. Entretanto, a organização deve ter ciência de que não existe uma fonte de vantagem competitiva que se sustente eternamente.

Pereira (2010, p.17), seguindo a linha de raciocínio de Porter (1990), conclui que as atividades de valor "são atividades físicas e tecnologicamente distintas através das quais uma empresa cria um produto valioso para os seus compradores".

Ao aprofundar nos estudos de Vantagem Competitiva (VC), Barney (1991) considera como VC, quando uma empresa cria mais valor que seus concorrentes, em um intervalo de tempo, considerando que: o valor criado é a diferença entre a disposição a pagar e o custo de oportunidade, lembrando que os concorrentes são aqueles que competem diretamente com a empresa, e que o intervalo de tempo esteja adequado ao ciclo de vida de desenvolvimento de recursos.

Observa-se que VC é um ganho que a empresa espera conseguir ao se posicionar no mercado a partir do valor que o seu produto pode proporcionar. Isto porque nem sempre o preço cobrado pelo produto ou serviço é o que o cliente está disposto a pagar. Segundo Hayashi-Jr, Ito e Gimenez (2015), se o cliente tiver a possibilidade de barganha, com certeza a utilizará para a redução de preço. O que pode auxiliar a empresa em manter o seu valor. Logo, sua VC é a dinâmica do mercado.

Teodoro, Przeybilovicz e Cunha (2014), informam que as empresas investem muito dinheiro para inovar, na busca constante pela VC sustentada, fazendo com que os gestores invistam em recursos estratégicos de difícil replicação em médio para longo prazo.

Mas, então, como obter a vantagem competitiva usando os altos investimentos feitos pelas organizaçóes? Segundo Barney (1991), a gestáo dos resultados da criação de valor é tão importante quanto a própria criação de valor e a gestão da organização deve reconhecer e desenvolver recursos e capacidades, compreendendo um período típico de gestão. Isso porque, afirmar 
que a empresa cria valor não necessariamente lhe confere $\mathrm{VC}$, já que somente comparando empresas é possível constatar a VC.

Uma empresa com vantagem competitiva (VC) pode explorar a diferença entre a máxima disposição a pagar de seus produtos e a média de mercado, cobrando um preço-prêmio. Esta estratégia de apropriação de valor resultará em margens mais altas. Neste sentido, a empresa que oferecer maior valor para o cliente poderá ter insumos e condiçóes diferenciadas de seus fornecedores. Deste modo, Brito e Brito (2012, p. 370) informam que "a apuração de lucro econômico dependerá ainda da barganha com fornecedores e da definição do custo de oportunidade da empresa”.

\section{GOVERNANÇA DE TECNOLOGIA DA INFORMAÇÃO}

Como pode ser observada, a VC está claramente posicionada como um antecedente do desempenho, trazendo diferentes resultados dependendo da estratégia de apropriação de valor das empresas, caracterizando-se como condiçáo insuficiente para o desempenho financeiro e para a maximização do lucro.

Já para agregar valor a um produto, deve-se lembrar que o conceito de valor se refere a aquilo que os compradores estão dispostos a pagar pelo que a empresa lhe oferece, ou seja, segundo Porter (1990, p.2), "cada indivíduo estabelece o valor do produto ou serviço adquirido em função do benefício agregado por este produto ou serviço”. Para Hayashi-Jr, Ito e Gimenez (2015, p. 91), em geral, "o valor é algo que pode ser desejado, necessitado, produzido e comercializado com possibilidades de lucro". Portanto,o valor de troca é afetado pelos custos de transação, já que o modo de governança da relação mais adaptada às características da transação gera maior valor na troca. Ainda segundo Hayashi-Jr, Ito e Gimenez (2015, p. 93), "O mecanismo de criação de valor é, portanto, influenciado pela economia dos Custos de Transação no que diz respeito às atividades de procurar e distribuir".

Quanto a tentar obter VC empregando a TI, Becker, Lunardi e Maçada (2012, p.18) afirmam que, embora existam fortes indícios de que a TI afeta positivamente o desempenho das organizaçóes, não são poucos os exemplos de empresas que gastaram enormes quantias em projetos tecnológicos malsucedidos. Surgem as questóes: como reduzir ou eliminar o risco de um projeto tecnológico, normalmente caro, ser malsucedido? Como reduzir o risco de vazamento de informação? Como estabelecer uma base de conhecimento formada por profissionais que atuaram no projeto? As respostas estáo no emprego de governança de TI (GTI). 
Segundo Weill e Ross (2004, p. 8), governança de TI (GTI) especifica os direitos de decisão e estrutura de responsabilidade para encorajar comportamentos desejáveis no uso de TI.

Becker, Lunardi e Maçada (2012) definem os objetivos de governança de TI como a operacionalização da função da TI na organização de forma mais eficiente e eficaz, sendo a maioria de suas regras e mecanismos, resultados do senso comum, da padronização, da experiência e das "melhores práticas" aceitas pelo mercado. Ou seja, a governança de TI (GTI) é uma parte integrante do processo de Governança Corporativa que, para desempenhar melhor o seu papel, aplica uma série de ferramentas desenvolvidas por órgáos e fundaçóes voltadas para este aspecto, como por exemplo, o International Standard Organization (ISO), o British Standard, entre outras organizaçóes.

Klein e Wiedenhöft (2013), informam que a GTI tem como princípios: transparência, equidade, prestação de contas, responsabilidade corporativa, comportamento humano, conformidade, desempenho, aquisição, e alinhamento estratégico. Portanto, observa-se, claramente que existe uma ligação entre Governança Corporativa e a governança de TI (GTI), na medida em que as organizaçôes são incentivadas a adotar princípios como transparência, equidade e prestação de contas. Para estes autores, a GTI consiste em aplicar os princípios da governança corporativa para gerenciar e controlar estrategicamente a TI, preocupando-se, principalmente, com o valor agregado pela TI ao negócio e a redução dos riscos associados à TI.

Mas, o que é governança de TI (GTI)? Para Gomes-Neto, Pereira e Mariano (2010), a GTI é um conjunto de práticas de gestão de TI que busca auxiliar no balanceamento de riscos e oportunidades em um ambiente altamente dinâmico, otimizando tomadas de decisão, controlando custos, pessoas, contratos, possibilitando aos clientes a garantia dos serviços fornecidos pela TI, bem como, especifica os direitos de decisão e responsabilidade na estrutura da organização, a fim de, obter o uso desejável de TI.

Ou ainda, para Barbosa et al. (2011), a GTI é um conjunto de práticas, padróes e relacionamentos estruturados, assumidos por executivos, gestores, técnicos e usuários de TI de uma organização, com a finalidade de garantir controles efetivos, ampliar os processos de segurança, minimizar os riscos, ampliar o desempenho, aperfeiçoar a aplicação de recursos, reduzirem os custos, suportar as melhores decisóes e consequentemente alinhar TI aos negócios.

\section{GOVERNANÇA DE TI EM BUSCA DE VANTAGEM COMPETITIVA}

Observa-se que a GTI herda os princípios de transparência, equidade, prestaçáo de contas e responsabilidade corporativa, oriundos da Governan- 
ça Corporativa, conforme dito pelos autores Gomes-Neto, Pereira e Mariano (2010) e Barbosa et al. (2011). Assim, os objetivos da GTI se tornam claros. São eles: proporcionar a utilização efetiva dos recursos, utilizar a TI para crescimento do negócio, proporcionar a redução de custo de tempo de manutenção da TI, proporcionar velocidade e eficiência nas mudanças, garantir o custo efetivo da TI, auxiliar na gestão de riscos, proporcionar a flexibilização do negócio, garantir a padronização dos sistemas e proporcionar simplicidade das situaçóes.

Para Barbosa et al. (2011), em um ambiente de negócios altamente competitivo e dinâmico é necessário um ambiente gerencial onde a TI deve apoiar as tomadas de decisão de forma rápida, constante e com custos cada vez menores, apontando como podem auxiliar a aumentar o grau de controle e automação dos processos corporativos, relacionado à Tecnologia da Informação e aos processos de gestão estratégicas e administrativas de uma organização.

Observa-se, portanto, que a GTI está relacionada à estratégia adotada pela empresa. Isto faz sentido principalmente quando se espera obter VC perante o mercado.

Para Klein e Wiedenhöft (2013), a GTI deve ser entendida como Governança Corporativa aplicada a TI. As responsabilidades da GTI são parte das responsabilidades da governança corporativa, tais como a orientaçáo e revisão das estratégias organizacionais, definição e acompanhamento dos objetivos e metas de desempenho de gestáo, garantia da integridade dos sistemas da organizaçáo e respeito pelos princípios da governança corporativa. Neste sentido, Marques e Mota (2013) informam que a GTI está contida na governança corporativa, uma vez que entre os ativos que precisam ser gerenciados estão os ativos informacionais.

Partindo dos conceitos de governança corporativa, governança de TI e vantagem competitiva, são cruzadas as informaçóes obtidas na literatura, tentando compor o seguinte panorama, de modo resumido, descrito na $f$ gura 1 a seguir. 
Figura 1: Visão macro da proposta da pesquisa.

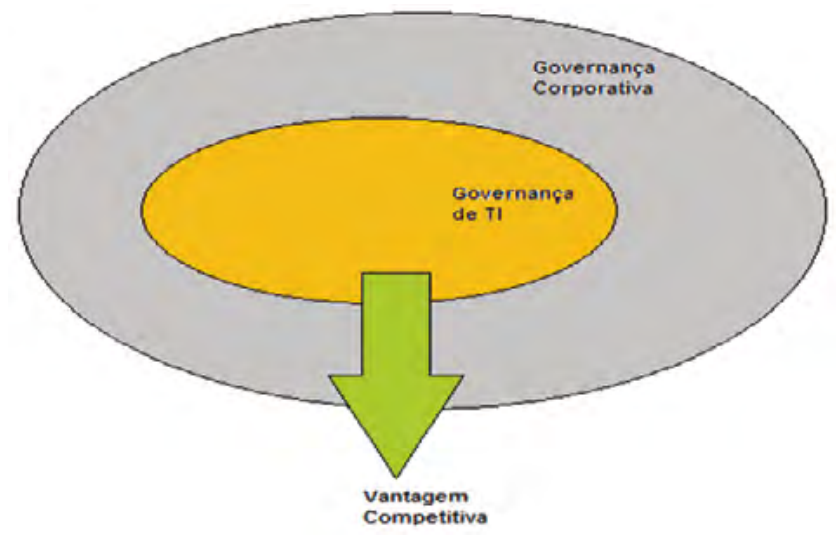

Fonte: Elaboração própria.

Pela figura 1, é possível observar que a vantagem competitiva é gerada a partir dos critérios e ferramentas da governança de TI, que fazem parte do processo de governança corporativa de uma organização.

Mas, quais as ferramentas de GTI são empregadas no sentido de orientar os dirigentes das organizaçóes sobre o uso efetivo e aceitável da TI? Em resposta a esta indagação, tem-se a publicação da norma ISO/IEC 27.0001:2013, pelo International Standard Organization, substituindo a norma ISO/IEC 38500, que reforça e estabelece os seguintes princípios de governança de TI: alinhamento estratégico, aquisição, desempenho, conformidade e comportamento humano.

Em concordância, os autores Becker, Lunardi e Maçada (2012), Klein e Wiedenhöft (2013) e Teodoro, Przeybilovicz e Cunha (2014), citam alguns dos mecanismos de GTI que podem ser destacados: presença de comitês, com participação da área tecnológica na formulação de estratégias corporativas; processos de elaboração e aprovação de orçamentos e projetos de TI; uso de frameworks tradicionalmente encontrados na literatura especializada que procuram alinhar os investimentos de TI com a missão, estratégia, valores e cultura organizacionais. Alguns destes frameworks são:

- Control Objectives for Information and Related Technology (COBIT). É um conjunto de diretrizes baseadas em auditoria para processos, práticas e controles de TI, voltado para redução de risco, com foco na integridade, na confiabilidade e na segurança da informação;

- Information Technology Infrastructure Library (ITIL).É uma biblioteca contendo padróes de boas práticas voltadas para o mundo da TI, unificando os termos comuns utilizados por profissionais de TI. Se aplicado 
de forma planejada, é capaz de diminuir - até eliminar - os anseios de clientes e usuários no que se refere à eficiência, eficácia e economia dos produtos e serviços de uma organização;

- ISO - International Standard Organization, através das normas ISO/ IEC 17799 e 27001 que estabelece princípios baseados em padróes consultivos, fornecendo orientaçóes gerais sobre o papel de um órgáo social, encorajando as organizaçóes a utilizar as normas apropriadas para segurança da Informação;

- Balanced Scorecard de TI (IT BSC), conectando as diretrizes traçadas entre as diversas áreas da organização com a TI e a direção da organização;

- PMI - Project Management Institute, através de procedimentos padróes ditados pelo PMBOK;

- CMMI - Capability Maturity Model Integration, modelo de melhores práticas na área de engenharia de software, criado para ajudar as organizaçôes a aprimorar seus processos, tornando-as mais maduras e eficientes, com aumento da qualidade dos produtos desenvolvidos;

- PRINCE2 - Segundo Tarouco e Graeml (2011), trata-se de uma metodologia desenvolvida a partir do PRTOMPTII, outra metodologia de projetos criada pela empresa Simpact Systems Ltd. Em 1975, a qual foi adotada pela CCTA (órgão do Governo Britânico), e que foi utilizado para os usuários melhorarem a sua gestáo sobre projetos de sistemas de informação;

- SEIS SIGMA - Segundo Tarouco e Graeml (2011), é uma metodologia oriunda da Motorola, cujo nome é originário da letra do alfabeto grego utilizada em estatística para simbolizar o desvio padrão, ou seja, uma medida para quantificar a variação e inconsistência de determinado processo.

Neste conjunto dos mecanismos mencionados, aparecem itens bastante amplos, como o COBIT ou a Norma ISO, que podem representar um conjunto de organismos, dada a sua amplitude. Para Klein e Wiedenhöft (2013, p. 3), "Outros mecanismos representam modelos ou melhores práticas, como é o caso do ITIL e do CMMI-SVC (Capability Maturity Model Integration for Services)”.

Para Becker Lunardi e Maçada (2012), os principais mecanismos e práticas de GTI são:

- Definição de papeis e responsabilidades. Isto implica na responsabilidade e no compromisso das pessoas envolvidas no desempenho organizacional;

- Comitês de TI, com a finalidade de acompanhar as diretrizes estratégicas da organizaçáo, buscando a excelência dos resultados. Os comitês mais comumente utilizados têm sido o comitê de estratégia de TI, o comitê diretivo de TI e o comitê de governança de TI; 
- Participação da TI na definição das estratégias corporativas, evitando que sejam realizados projetos caros, inviáveis, que sejam propensos a desistências e que tenham baixo rendimento ou retorno financeiro destes investimentos;

- Escritório de projetos de TI, no apoio ao gestor, de modo a fazer com que o projeto agregue valor à organização. $\mathrm{O}$ seu papel é desenvolver e fazer cumprir padróes e procedimentos para projetos e programas dedicados a TI. O uso desse mecanismo oferece benefícios para a organização, como o monitoramento do uso e a aderência dos padróes da tecnologia e, também, proporciona a coleta e relatos do progresso e o desempenho dos projetos em andamento;

- Planejamento Estratégico de Sistema de Informação. Sua função é analisar as especificidades e discutir como a TI pode ser utilizada para obter vantagem competitiva, além de tratar de assuntos ligados à sua utilização e ao seu gerenciamento;

- Acordo de Nível de Serviço ou Service Level Agreement (SLA) e Gestão do Nível de Serviço ou Service Level Management (SLM).Proporcionam os seguintes benefícios para as empresas: redução de custos vinculados a diferentes atividades operacionais, melhoria da qualidade dos serviços, acesso a soluçôes de classe internacional e rapidez na implementação de novos processos;

- Indicadores e métricas de desempenho;

- Análise de viabilidade de projetos de TI. O uso de métodos para avaliar a viabilidade dos projetos de TI permite à organização analisar os benefícios e custos estimados nos projetos, podendo antecipar se determinado investimento vale a pena ou não e priorizá-lo;

- Avaliação pós-implementação, evitando que, por exemplo, o sistema implantado tenha muitas falhas e que estas não sejam sanadas em tempo hábil, destinando o produto implantado ao fracasso;

- Envolvimento da área de TI nos negócios. A troca de ideias e a clareza na compreensão do que é necessário para garantir o sucesso das estratégias corporativas sáo essenciais para que os investimentos realizados em TI estejam de acordo com as necessidades da organização;

- Comunicaçáo efetiva. Baseada na adoção de diferentes mecanismos de comunicação é muito importante para que haja uma boa governança de TI. Tais mecanismos objetivam divulgar as orientaçóes sobre os processos relativos à GTI, as suas decisóes e aos comportamentos desejáveis por meio da empresa;

- Compartilhamento da aprendizagem, através de bancos de conhecimento, por exemplo. 
Ainda na busca por uma resposta sobre como a GTI auxilia as organizaçôes na obtenção de VC, Becker, Lunardi e Maçada (2012), a concluem que as empresas que adotaram mecanismos formais de GTI melhoraram significativamente seu desempenho organizacional quando comparadas às empresas sem GTI, no período analisado, especialmente no que se referem a medidas de rentabilidade, tais como Return on Assets (ROA), Return on Equity (ROE) e Margem Líquida, evidenciando a correlação entre a adoção de mecanismos de governança de TI e um melhor desempenho financeiro das empresas.

Para Pereira (2010) a ligação entre a governança de TI e vantagem competitiva está na relação existente na Cadeia de Valor das Empresas e o alto investimento tecnológico realizado por elas.

Chi e Sun (2015), fundamentados nos conhecimentos de Visão Baseada em Mercados (VBM) e Visão Baseada em Recursos (VBR), na intenção de estabelecer a ligação entre governança de TI e vantagem competitiva nas organizaçóes, buscaram integrar as seguintes teorias: Teoria do processo, Teoria complementar de ativos, Teoria de recursos de TI e Teoria de capacidade de TI, resultando no modelo de Processo de como a TI impacta a vantagem competitiva das Empresas. Este modelo tem como premissas: julgamento se a empresa tem o pré-requisito para usar TI para obtenção de VC sustentável; as capacidades de TI das empresas, através de aprendizagem organizacional devem ser cultivadas; Foco no investimento em recursos complementares, já que a TI por si só não é garantia para obtenção de VC.

Estas premissas são validadas nas pesquisas de Vieira e Rodriguez (2005) quando estabelece uma relação funcional da GTI em busca da VC, e chega à conclusão de que a verdadeira fonte de vantagem competitiva da TI está no entendimento que a TI é uma ferramenta de suporte ao negócio de uma empresa e que devem ser feitas análises das necessidades tecnológicas da organizaçáo e uma avaliaçáo dos riscos de investimentos.

\section{CONSIDERAÇÓES FINAIS}

Costa e Rosini (2015) informam que é importante destacar que a capacidade de inovação e respostas à mudança no ambiente de TI depende em grande parte da rotina de trabalho de suas equipes. Sendo assim, a renovação dos processos de trabalho está diretamente ligada à capacidade da empresa em gerar competências organizacionais a partir das competências individuais. Outro ponto a considerar é que o envolvimento, a transparência, a responsabilidade e a integração dos colaboradores e da alta gerência são fatores de sucesso para o correto mapeamento, desenho e alinhamento de processos.

Porém, náo se pode negar que o sucesso de qualquer estratégia está no compromisso dos gestores em realizar uma boa gestão financeira, no emprego adequado da GTI e no envolvimento dos stakeholders para a obtenção de VC. 
Então, respondendo à questão de como a GTI auxilia a organização na obtenção de VC temos as consideraçóes, conforme o modelo de Chi e Sun (2015):

- A TI sozinha não pode ajudar as empresas a alcançar VC sustentáveis, mas as empresas podem obter vantagens usando a TI para alavancar os ativos complementares da empresa como novos processos de negócios, novos modelos de negócios, comportamento de gestão, cultura organizacional ou treinamento;

- Os recursos de TI heterogêneos são a base para ganhar VC;

- As despesas de TI devem ser úteis e potencialmente produzir ativos de TI para depois, esses ativos ajudarem a empresa a melhorar seu desempenho;

- As empresas precisam fazer uma análise dos principais problemas e desafios que enfrentam e precisam resolvê-los. Pode ou náo ser com a ajuda da TI;

- Foco no investimento em recursos complementares.

Finalmente, espera-se que esta pesquisa possa fornecer subsídios para futuras pesquisas a serem realizadas por professores, alunos e pesquisadores acadêmicos, bem como auxiliar empresários, gestores e administradores nos processos de tomada de decisão. É sugerido, também, que mais pesquisas quantitativas e qualitativas sejam feitas buscando maior aprofundamento e evidências no que a literatura vem apresentando.

\section{REFERÊNCIAS}

BARBOSA, Andressa Munhoz et al. Governança em TI: COBIT; ITIL. $\boldsymbol{R e}-$ vista científica Eletrônica de Administração. Garça, São Paulo. Ano XI, n.19. 22 Jan. 2011. Disponível em: http://faef.revista.inf.br/imagens_arquivos/arquivos_destaque/b4K1BphABn6CaKb_2013-5-3-11-17-0.pdf. Acesso em: 8 mar. 2016.

BARNEY, Jay. Firm resources and sustained competitive advantage. Journal of Management. v. 7, n. 1, p. 99-120, 1991. Disponível em: http://business.illinois.edu/josephm/BA545_Fall\%202011/S10/Barney\%20(1991).pdf. Acesso em: 05 out. 2015.

BECKER, João Luiz; LUNARDI, Guilherme Lerch; MAÇADA, Antônio Carlos Gastaud. Um estudo empírico do impacto da governança de TI no desempenho organizacional. Produçáo. Rio Grande do Sul, v. 22, n. 3, p. 612624, mai/ago, 2012. Disponível em: http://www.scielo.br/pdf/prod/v22n3/ aop_t6_0007_0374.pdf. Acesso em: 01 out. 2015.

BRITO, Luiz Artur Ledur; BRITO, Renata Peregrino de. Vantagem Competitiva e sua Relação com o Desempenho: uma Abordagem Baseada em Valor. Revista de Administraçáo Contemporânea - RAC. Rio de Janeiro, v.16, n. 3 
Art. 2, p. 360-380, mai/jun, 2012. Disponível em: http://www.scielo.br/pdf/ rac/v16n3/v16n3a03.pdf. Acesso em: 01 out. 2015.

CHI, Jiayu; SUN, Ling. IT and Competitive Advantage: A study from Micro Perspective.Modern Economy. n. 6, p. 404-410, mar. 2015. Disponível em: http://file.scirp.org/pdf/ME_2015032414563326.pdf. Acesso em: 20 out. 2017.

COSTA, Rogério Fernandes da; ROSINI, Alessandro Marco. Estudo do impacto da Governança da Tecnologia da Informação no desempenho das Empresas brasileiras: Uma análise a partir da perspectiva dos executivos, usuários e membros de equipes de TI. Revista Future Studies Research Journal. São Paulo, v. 7, n. 2, p. 156-178. dez. 2015. Disponível em: https://revistafuture. org/FSRJ/article/viewFile/155/328. Acesso em: 12 abr. 2017.

GOMES-NETO, Bruno Jacob; PEREIRA, Fábio Luiz Gomes; MARIANO, Sandra Regina Holanda. Avaliação da Governança Corporativa de TI e uma comparação entre os modelos e mercado. In: XXX Encontro Nacional de Engenharia de Produção.2010, São Carlos, SP. Maturidade e desafios da Engenharia de Produção: competitividade das empresas, condiçóes de trabalho, meio ambiente. Disponível em: http://www.abepro.org.br/biblioteca/ enegep2010_TN_STO_113_739_16748.pdf. Acesso em: 8 mar. 2016.

HAYASHI-JR, Paulo; ITO, Nobuiuki Costa; GIMENEZ, Fernando Antônio Prado. Reflexão e imbricação das atividades da firma com seus valores de uso e de troca. Revista Pensamento Contemporâneo em Administraçáo - RPCA. Rio de Janeiro, v. 9, n. 1, p. 90-106, jan/mar, 2015. Disponível em: http:// www.uff.br/pae/index.php/pca/article/view/521. Acesso em: 25 set. 2015.

KLEIN, Rodrigo Hickmann; WIEDENHÖFT, Guilherme. Identificação de mecanismos para atender os objetivos e princípios de Governança de TI na visão de profissionais da área. Revista Eletrônica de Sistemas de Informação. Rio Grande do Sul, v. 12, n. 2, art. 1, set. 2013. Disponível em: http://189.16.45.2/ ojs/index.php/reinfo/article/view/1728/pdf. Acesso em: 21 nov. 2015.

LIPPMAN, Steven A., RUMELT, Richard P.. A bargaining perspective on resource advantage. Strategic Management Journal. Califórnia, v. 24, n. 11, p. 1069-1086. Ago. 2003. Disponível em: http://onlinelibrary.wiley.com/ doi/10.1002/smj.345/pdf. Acesso em: 20 mar. 2016.

MARQUES, Érico Veras; MOTA, Ariane Firmeza. Governança da Tecnologia da Informação: Um estudo bibliométrico em eventos e periódicos brasileiros. Revista Eletrônica de Sistemas de Informaçáo. Ceará, v. 12, n. 2, art. 2, dez. 2013. Disponível em: http://www.spell.org.br/documentos/download/28093. Acesso em: 21 nov. 2015. 
MELO, Daniel Reis Armond de. A importância da tecnologia da informação nas estratégias das organizações contemporâneas: breve revisão de literatura. In: V Congresso Virtual Brasileiro de Administração - CONVIBRA, 2008. Disponível em: http://www.convibra.com.br/2008/artigos/412_0.pdf. Acesso em: 07 set. 2016.

PEREIRA, Rogério Tadeu Teixeira. Obtendo Vantagem Competitiva através das Ferramentas de Governança de TI. 2010. Trabalho de Conclusão de Curso (MBA em Estratégia Empresarial). Universidade Nove de Julho. Disponível em: https:/pt.scribd.com/document/48926966/TCC-Obtendo-Vantagem-Competitiva-atraves-das-Ferramentas-de-Governanca-de-TI. Acesso em: 20 out. 2017.

PORTER, Michael E. Competitive Advantage of nations: Gaining, creating and sustaining a superior performance. New York: Simon \& Schuster, 1990. VIEIRA, Daniele Machado; RODRIGUEZ, Martius Vicente Rodriguez Y. Governança de TI como Suporte para as estratégias competitivas da Organização, A. In: SEGET - Simpósio de Excelência em Gestão e Tecnologia, 2., 2005. Resende, RJ. Anais AEDB. Resende: AEDB, 2005. p.1035-1043. Disponível em: http://www.aedb.br/seget/arquivos/artigos05/240_artigo1_seget. pdf. Acesso em: 06 abr. 2017.

TAROUCO, Hiury Hakin; GRAEML, Alexandre Reis. Governança de Tecnologia da Informação: Um panorama da adoção de modelos de melhores práticas por empresas brasileiras usuárias. Revista de Administraçáo da Universidade de Sáo Paulo - RAUSP, v. 46, n. 1, p. 7-18. São Paulo, mar. 2011. Disponível em: https://www.google.com.br/url?sa=t\&rct=$\mathrm{j} \& \mathrm{q}=\&$ esrc $=$ s \&source $=$ web $\& \mathrm{~cd}=1 \& v e d=0$ ahUKEwiL5Ke-qf_WAhVFEZAKHYJmBxQQFggnMAA\&url=https\%3A\%2F\%2Fwww.revistas.usp. br\%2Frausp\%2Farticle\%2Fdownload\%2F 44521\%2F 48141\&usg=AOvVaw3j-ENpNu1IMe9eMeXDtJNE. Acesso em: 20 out. 2017.

TEODORO, Allexandre Nishioka; PRZEYBILOVICZ, Érico; CUNHA, Maria Alexandra. Governança de Tecnologia da Informação: Uma investigação sobre a representação do conceito. Revista de Administração. São Paulo, v. 49, n. 2, p. 307-321, jun. 2014. Disponível em: http://www.scielo.br/ scielo.php?pid=S0080-21072014000200008\&script=sci_abstract\&tlng=pt. Acesso em: 28 mar. 2017.

WEILL, Peter; ROSS, Jeanne W. IT Governance:How top performers manage IT decision rights for superior results. Harvard Business School Press. Boston, Massachussets, 2004. 
